\title{
Almost Fifty Years of URSI ${ }^{1}$
}

Address at banquet, December 13, 1960, of URSI-IRE Meeting, Boulder, Colo.

\section{J. Howard Dellinger}

(January 19, 1961)

"URSI"-If I were Professor Kennelly, I would automatically say "URSI, the bears." Although a professor of electrical engineering, being a Harvard professor, Kennelly could not forget his Latin so to him URSI was always the bears. That remarkable man was one of the early presidents of URSI; was the discoverer of the ionosphere (some of you have heard of the "Kennelly-Heaviside layer"), and was the father of the coded Ursigrams.

All of us are in on a good thing. We are in on the ground floor because "URSI's almost 50 years" include three-fourths of the entire history of radio and practically all of the history of radio science. This is true even though the greatest single event in the history of radio science was its beginning, just a hundred years ago. That was Maxwell's discovery by means of pure theoretical science, that electromagnetic waves could be produced by electrical apparatus and that their velocity would be the velocity of light. Maxwell published this in 1864. Once this giant stride had been taken, however, science had little to do with radio for the next 50 years. The world indeed took Maxwell's hint and went about the business of producing and using those electromagnetic waves from electrical apparatus, in other words, radio. There was of course some research on the means of generating and detecting the waves, but little in the way of scientific study either of the devices or the behavior of the radio waves or the medium through which they are propagated.

An awakening consciousness that science and radio should get together was what led to the formation of URSI. The first step was taken in 1913, about the same time, incidentally, as the beginning of the Institute of Radio Engineers. In that year a group of nine scientists from six European countries met in Brussels and determined to establish an "International Commission on Scientific Wireless Telegraphy," to undertake research on wave propagation. World War I prevented the organization from functioning. After the war, in 1919, the members of the group saw that the need for organizing radio science had greatly increased and they did establish the "International Union of Scientific Radio Telegraphy" with approximately the present objectives and form of the URSI. The first General Assembly was held in Brussels in 1922. We radio scientists

Editor's note: Dr. Dellinger is an honorary president of the International Scientific Radio Union (URSI), was the first chief of the Central Radio Propagation Laboratory, and was president of the Institute of Radio Engineers in 1925 have been having fun ever since, talking to and learning from one another.

The 1963 General Assembly in Japan will celebrate the 50th anniversary of the 1913 beginning. It could well recognize at the same time the centenary of radio's origin, Maxwell's theory of electromagnetism. That supreme achievement is to be celebrated also at the 1965 Plenipotentiary Conference of the International Telecommunication Union.

Radio today talks an entirely different language from that of 1913. You note that the organization formed that year dealt with "wireless," not "radio." Also in those days we always described the frequencies we used by means of wavelength in meters; nobody dreamed of a megacycle, and what we know as a frequency meter was called a wavemeter. Also, the "ionosphere" had not been heard of, what we knew was the "Kennelly-Heaviside layer." To intrude a personal note, I had considerable to do with the change to all three modern expressions: radio, kilocycle, ionosphere. This I was able to do by virtue of my position as head of the radio work of the National Bureau of Standards. In the U.S. the change in common practice from "wireless" to "radio" came in about 1912 to 1916, from wavelength to frequency about 1916 to 1920 , and from "Kennelly-Heaviside layer" to "ionosphere" in about 1932. In Bureau papers published in the early thirties, it became more and more unsatisfactory to talk about the "Kennelly-Heaviside layer" when we regularly got reflections from two or more layers. These changes in terminology came somewhat later in other countries. It is interesting to note that the changes from "wireless" to "radio," and from wavelength to frequency, were resisted by the British and are to this day. The British just don't like change.

Not only the language but the ideas were different in the days of URSI's beginnings. Radio telegraphy was carried on by means of damped waves, and radio telephony which requires continuous waves was just beginning to be experimented upon. The damped waves were in use because only they could be generated with enough power. Damped waves are a terrible nuisance, not only in practice because of their great interference production (like pulses) but also in all calculations and theory. The principal thing you had to deal with was a quantity called the logarithmic decrement, a measure of the rate at which each train of waves or current oscillations fell off to zero. Well, the decrement of a circuit was 
proportional to the ratio of resistance to reactance or the reciprocal of $Q$, the sharpness of resonance; the trouble was you had to take account of this quantity for the damped current oscillations as well as for the circuits. The principal instrument a radio inspector had to carry around was a decremeter, a device for measuring decrement as well as wavelength.

When URSI was beginning we were just developing reliable sources of continuous waves. Not only did this make radio telephony possible but there was dawning hope of that bugbear, decrement, disappearing from radio calculations. Anticipating the demise of damped waves, the National Bureau of Standards during World War I prepared the first radio textbook which based radio theory on straight alternating-current theory, giving damped waves only minor and separate treatment. This was Bureau Circular 74, Radio Instruments and Measurements." Issued 42 years ago, it is still being sold by the Government Printing Office. I suppose it is the oldest of the Government's best sellers.

We tried various ways of producing continuous waves (Alexanderson's high-frequency alternator, are generator, and thermionic tube). J. A. Fleming of England had invented the two-electrode thermionic tube, and used it as a radio detector, in 1899 . In 1906 De Forest put in the third electrode and the development of the electron tube as oscillator and amplifier proceeded steadily from then on. The way was clear for radio telephony, for precise radio measurements, for penetrating the mysteries of radio wave propagation, and for the new world of electronics. The advances have snowballed ever since.

Two of the thirteen General Assemblies of the URSI were held in the U.S. The second was in Washington in 1927, and the twelfth here in Boulder in 1957. I think E. V. Appleton and I are the only participants in the 1927 meeting who are still active in URSI. Another participant was the late Samuel S. Kirby (father of Bob Kirby who is present this evening); he was a very active URSI man and was secretary of the USA National Committee, which we then called the American Section. Also among those present was the late Dr. B. van der Pol, eminent mathematician who at the 1927 meeting initiated the Commission on Radio Waves and Circuits (called at first Radio Physics) and was its chairman for 25 years. Distinguished participants who are still living included Dr. A. H. Taylor, E. F. W. Alexanderson, H. Pratt, Dr. P. Le Corbeiller, Dr. G. C. Southworth, Dr. G. Breit, Dr. M. Tuve, Dr. C. B. Jolliffe. Also present were Dr. L. W. Austin and Professor A. E. Kennelly, both of whom served terms as chairman of the USA National Committee and president of the URSI itself. The president in 1927 was the French General G. Ferrié and the secretary general was professor $R$. B. Goldschmidt of Belgium. Professor Goldschmidt was the father of URSI. When the predecessor organization was founded in 1913 he offered to build a special radio transmitting station for research purposes, and he financed the URSI in its early years. General Ferrié was a remarkable leader. He was the first president and provided the guide lines of growth for the first 10 years. He was the finest type of gentleman, a lovable character and an inspiring scientist. Dr. Austin was the second president of URSI. He was the first chairman of the USA National Committee and was the American pioneer in radio research. He was doing this work, on the staff of the U.S. Navy at the National Bureau of Standards, as early as 1905 , and was active in it until his death in 1932. He was most famous for his semiempirical formula for long-distance received field strength for low frequencies (LF and VLF).

Don't start to worry. I am not going to recite the history of the URSI. That is largely available in the URSI Information Bulletins, and a comprehensive publication on it will be issued as part of the golden anniversary celebration of 1963 .

The list of places where the General Assemblies have been held will convince you that we who are designated to attend these affairs are fortunate. Besides Brussels and Washington they have included Copenhagen, London, Venice, Paris, Stockholm, Zurich, Sydney (Australia), The Hague, and Boulder. Besides giving the participants a good time, they have had a mighty influence in coordinating and expediting the extraordinary advances of radio; and, just by the way, also contributing to that good international understanding which is the prerequisite of world peace.

While recounting the privileges that URSI has brought to me, I might add that I had the honor of serving in the USA National Committee as Secretary from 1920 to 1933, Vice Chairman from 1933 to 1940, and as Chairman from 1940 to 1949 ; and in the international URSI as Chairman of the Commission on Radio Wave Propagation from 1934 to 1946, as Chairman of the Commission on Radio Measurement Methods and Standards from 1946 to 1952, as Vice President from 1934 to 1952 , and as Honorary President since 1952.

Since my service as URSI Vice President spanned the period of World War II, I had the opportunity to help in keeping the organization alive during that distressful period. For four years after Germany invaded Belgium in May, 1940, mail service between England and Belgium was cut off, so President Appleton in London and the Secretariat in Brussels had no communication. URSI work in the $\mathrm{Na}$ tional Committees in the various countries also declined to nearly zero. I wrote to the Brussels Secretariat in August 1940. I received a reply two months later from Miss Straetmans, the office assistant, saying that she was trying to keep the office going but that Commander Dorsimont (Acting Secretary General) and Major Herbays (Editor) were prisoners of war in Germany. She gave me their addresses; I wrote to them and also tried to help Miss Straetmans' efforts to get them released. Mrs. Dellinger and I sent them food parcels, a common practice in the war years. I also wrote to the chairmen of various National Committees urging 
them to keep National Committee work going if possible. The spark of life was not extinguished. A General Assembly was held in Paris in September 1946, a year after the end of the war.

I wish there were time to tell you of many events and many people that have been in the forefront these 50 years. I will give you merely the titles of two great events, the Second Polar Year (1932 to 1933) and the International Geophysical Year (1957 to 1958). The URSI is now recognized as the natural leader of great enterprises like the IGY. The fine work done by United States research people, and may I say especially you folks here in Boulder, is a major ingredient in our present prestige. Another ingredient is the man who served as president of the URSI the past three years and as president of the International Council of Scientific Unions just before that, Lloyd V. Berkner. We who belong, or have belonged, to the National Bureau of Standards radio work, can take pride in the fact that he was one of us for several years (this was some 30 years ago).

The prestige and the glory of URSI mainly derive from the fact that it really accomplishes its objective: the worldwide coordination of radio research. It is the place where radio science presents its findings. If you include the meetings of the national sections as well as the General Assemblies, it can be said that in the URSI meetings you hear the first announcement of everything new in radio science. Sometimes a great advance is not recognized as such when first presented. To mention one example: Karl Jansky described at a U. S.-URSI meeting in 1932 how he had received extraterrestrial radio waves and from their diurnal variation in direction identified their source in the Milky Way. We did not know we were witnesses to the start of an extraordinary new branch of human knowledge, radio astronomy.

I said that all of us are in on a good thing. It's not only because we are privileged to be the pioneers but because of the tremendous scope of our enterprise. The word "radio" does not tell the whole story. I am one of those who have kept the IRE from changing its name as more and more fields were added. The new fields do use radio techniques, so there is justification, even wisdom, in not changing the name. As a result, in IRE as well as in URSI, we have electronics, and what a field that is! Did you ever go through a modern airplane factory and see what there is between the gleaming outside and the glistening interior of the cabin? What you see is an amazing complex of the wires and fittings and devices of electronics. Well, URSI also has cybernetics and information theory and computers, and space communication and telemetry. Not only will radio with its branches, electronics and all, become the greatest of the industries, it will absorb most industry. I have been informed that electronics in the U.S. is already a bigger industry than agriculture.

The scientific side of all this belongs to URSI, and everybody knows that without the science these things would not exist. I am not implying that
URSI is a perfect organization. It is an evolving organization, changing as the needs of radio science change and as more men enter it. There is ample opportunity ahead, immediately and also later, for creative work in adapting URSI to this changing world.

It seems likely that the next great step forward in science as a whole will come from our field, radio. I am thinking of what radio astronomy is doing and is leading to. I do not think men are ever going to go out among the stars in spaceships. (We shall probably go all around the solar system; not out among the stars: other creatures, not men, may do even that.) But we are going out on radio waves; and with our radio telescopes farther than with optical telescopes.

At least one major and respectable radio astronomy observatory has a regular listening schedule for possible signals from intelligent beings somewhere in the universe. Many scientists ( $\mathrm{I}$ among them) believe that there are myriads of planets of stars other than our sun on which there is life. Probably very many have life of more advanced character than mankind. Probably many are sending out signals with the idea of contacting life on other worlds. I have heard them credited with the idea of trying to contact us - No! Although intelligent, they never heard of us. Until very recently most of us had only an amused tolerance for any such ideas. By the way, the National Bureau of Standards continues to receive every once in a while an inqury from somebody (a different person each time) about alleged signals, described in meticulous detail, which were supposed to have been recorded at the Bureau in 1924 from Mars. That was a false rumor. But scientifically organized efforts to receive intelligent signals from the depths of space may very well be rewarded some time. It may happen some centuries hence, it could happen tomorrow.

Another profound effort of the largest radio observatories is to reach the farthest observable parts of the universe. The universe is commonly thought of as expanding, constantly carrying galaxies out beyond the distance where their radiations can ever reach us, so no improvements in radio or other telescopes can ever observe them. Improvements have already taken us more than half way out to that limit. We are on the threshold of finding out whether the universe had a beginning or is being: continuously created. If it had a beginning, the number of galaxies in a given volume of space was (according to the expansion theory) much greater near the beginning than now. Well, when we look out upon very distant galaxies, because of the finite velocity of light we see them as they were nearer the beginning. At a distance of several billion light-years, then, there should be more galaxies than in the same volume of space nearer us. But if, on the other hand, creation is and always has been going on, new galaxies are always being formed and their average number in a given space is presumably the same throughout the universe. Evidence bearing 
on this is obtained slowly and with difficulty. It is one of the direct concerns of URSI and was one of the subjects of the General Assembly at London this year.

The cosmological problem can be attacked by radio in another way. If creation is continuous, the first step in the process is the emergence (or creation) of hydrogen atoms at a slow rate throughout space. Since these radiate on a frequency of $1,420 \mathrm{Mc} / \mathrm{s}$, it is quite possible that the presence of such hydrogen in space between the galaxies will be observed by radio telescopes.

The implications of an imminent solution of the cosmological problem stagger the imagination. They could lead to a step in the understanding of the universe comparable to those taken by Maxwell and by Einstein.

In conclusion, we tread a giant stage, don't we? And don't we have great fun doing it? The URSI meetings let us come out from our laboratories, and talk and listen. Lest we take ourselves too seriously in all this, I'd like to close with a quotation from a great astronomer who had some ideas that should help. He was the most noted of Persian astronomers. Here are three of the rubais of Omar Khayyam:

"Myself when young did eagerly frequent

Doctor and Saint, and heard great argument About it and about; but evermore

Came out by the same Door where in I went.

"With them the seed of Wisdom did I sow, And with mine own hand wrought to make it grow; And this was all the Harvest that I reap'd-

'I came like Water, and like Wind I go.'

"The Revelations of Devout and Learned Who rose before us, and as Prophets burn'd, Are all, but Stories which, awoke from Sleep They told their comrades, and to Sleep returned."

(Paper 65D4-134) 